Bangladesh Journal of Neuroscience 2012; Vol. 28 (2) : 81-87

\title{
Sodium Valproate is More Effective than Pizotifen in the Prophylaxis of Migraine Patients
}

\author{
MD MASUD RANA ${ }^{1}$, AKM ANWARULLAH $^{2}$, QUAZI DEEN MOHAMMAD ${ }^{3}$, MD RAFIQUL ISLAM $^{2}$, \\ HASAN ZAHIDUR RAHMAN ${ }^{4}$, MONIRUZZAMAN BHUIYAN ${ }^{4}$, FERDOUS JAHAN ${ }^{5}$, \\ HASAN IMAM ${ }^{5}$, AKM SHOAB ${ }^{6}$, SHARIF UDDIN AHMED ${ }^{7}$, ABDULALIM $^{7}$, SAMSUN NAHAR $^{8}$
}

\begin{abstract}
:
Background and objectives: Migraine is now ranked as number 19 among all diseases causing disability by $\mathrm{WHO}^{1}$ which is characterized by recurrent attacks of various combinations of headache and neurological, gastrointestinal and autonomic symptoms ${ }^{2}$ accompanied by photophobia, phonophobia and vomiting ${ }^{3}$. The treatment of migraine involves acute, preventive drugs and non-pharmacological strategies. The basic principle in management of migraine is avoiding the trigger factors, blocking the mediators and splinting the end organ ${ }^{4}$. Though there is no significant curable treatment but there are some internationally proven and well accepted prophylactic medication which reduces headache severity, frequency, duration and risk for rebound 5 . Sodium valproate and pizotifen are commonest of them ${ }^{6}$, where sodium valproate is more effective than pizotifen in the prophylaxis of migraine patients. Methods: This study was a single blind randomized clinical trial carried out in the neurology outpatient department of Bangabandhu Sheikh Mujib Medical University, Dhaka (BSMMU) for the period of 2 years, among adult patients between the age of 16-50 years. Results: A total of 120 patients were included \& divided into two groups such as group-A(60 patients) treated by sodium valproate \& group- $B$ (60 patients) treated by pizotifen for a period of 6 months and followed up every two months for 3 times and showed sodium valproate is more effective than pizotifen. Conclusion: This study permit to conclude that efficacy of sodium valproate is more than pizotifen in the prophylaxis of migraine patients.
\end{abstract}

Key words: migraine ,sodium valproate, pizotifen, prophylaxis.

Introduction:

Migraine is now ranked by the World Health Organization as number 19 among all diseases causing disability world-wide ${ }^{1}$. The exact cause is unknown but a number of factors trigger a migraine headache e.g. sensory stimuli, streneous exercise \& physical exertion, inadequate posture or stress in neck, hormonal fluctuation, foods-drinks \& additives, dehydration, insufficient sleep \& skipping or missing meal ${ }^{7}$. The exact pathogenesis is still unclear but following possible theories are responsible like vascular theory, neural theory, 5HT theory, dopamine theory \& some other theories ${ }^{8-}$ 10. It is an episodic primary headache disorder characterized by recurrent attacks of various combinations of headache and neurological, gastrointestinal and autonomic symptoms ${ }^{2}$. Migraine is a common condition, annually affecting

1. Medical Officer, Department of Neurology, Bangabandhu Sheikh Mujib Medical University, Dhaka

2. Professor, Department of Neurology, Bangabandhu Sheikh Mujib Medical University, Dhaka

3. Professor \& Head of Department of Neurology, Dhaka Medical College, Dhaka

4. Associate Professor, Department of Neurology, Bangabandhu Sheikh Mujib Medical University, Dhaka

5. Medical Officer, Department of Medicine, Bangabandhu Sheikh Mujib Medical University, Dhaka

6. Consultant Medicine, Rajnagar Upazila Health complex Moulovibazar. Bangladesh

7. $\mathrm{MD}$ (Neurology)student, Department of Neurology, Bangabandhu Sheikh Mujib Medical University, Dhaka

8. Professor, Department of Physical medicine, Bangabandhu Sheikh Mujib Medical University, Dhaka 
$12 \%$ of the United states population, including $18 \%$ of women, $6 \%$ of men and $4 \%$ of children. Lifetime prevalence of migraine in women in the United States exceeds $25 \%$. The prevalence of migraine has not changed since 1989, which was based on evidence from three large studies: American Migraine study-I, American Migraine Study-II and American Migraine Prevention and prevalence study. The basic principle in management of migraine is avoiding the trigger factors, blocking the mediators ${ }^{4}$. Sodium valproate and pizotifen can be used in the prophylaxis of migraine and the potential effectiveness of sodium valproate in migraine prophylaxis is well established.

\section{Materials and Methods:}

This study was a single blind randomized clinical trial carried out in the department of neurology at
BSMMU, Dhaka from January 2010 to December 2011 for a duration of two years among patients of both sexes between 16-50 years who presented with migraine and were enrolled in this study. Migraine patient were selected according to INTERNATIONAL HEADACHE SOCIETY (IHS) criteria who were not on prophylactic medication $\&$ patients having hepatic or renal impairment, pregnancy and prostatism were excluded from the study.

\section{Observation and Results:}

A total of 120 patients were included as study population and were divided into two groups, groupA (60 patients) and group-B(60 patients). The group-A took sodium valproate (400-1200 mg/day) and the group-B took pizotifen (0.5-3.00 mg/day) for total 6 months duration.

Table-I

Distribution of the patients by age $(n=120)$

\begin{tabular}{|c|c|c|c|}
\hline \multirow[t]{2}{*}{ Age $(y)$} & \multicolumn{2}{|c|}{ Group } & \multirow[t]{2}{*}{ p value } \\
\hline & Group A (Sodium valproate) & Group B (Pizotifen) & \\
\hline$<20$ & $14(23.3)^{\#}$ & $15(25.0)$ & \\
\hline $20-29$ & $23(38.3)$ & $22(36.7)$ & \\
\hline $30-39$ & $16(26.7)$ & $17(28.3)$ & \\
\hline 40 and above & $7(11.7)$ & $6(10.0)$ & \\
\hline Total & 60 (100.0) & 60 (100.0) & $0.983^{*}$ \\
\hline
\end{tabular}

*t test was done to measure the level of significance.

\#Figure within parentheses indicates percentage

Table II

Distribution of the patients by sex $(n=120)$

\begin{tabular}{lccc}
\hline Sex & Group A (Sodium valproate) & Group B (Pizotifen) & p value \\
\hline Male & $11(18.3) \#$ & $11(18.3)$ & 1.000 \\
Female & $49(81.7)$ & $49(81.7)$ & \\
Total & $60(100.0)$ & $60(100.0)$ & \\
\hline
\end{tabular}

${ }^{*}$ Chi-square test was done to measure the level of significance.

\#Figure within parentheses indicates percentage. 
Table III

Distribution of the patients by severity before treatment

\begin{tabular}{lccc}
\hline Severity & Group A (Sodium valproate) & Group B (Pizotifen) & p value \\
\hline Moderate & $21(35.0)$ & $19(31.7)$ & 0.699 \\
Severe & $39(65.0)$ & $41(68.3)$ & \\
\hline Total & $60(100.0)$ & $60(100.0)$ & \\
\hline
\end{tabular}

${ }^{*}$ Chi-square test was done to measure the level of significance.

Figure within parentheses indicates percentage

Table-I shows in group A majority were in the age group of $20-29$ years which was 23 (38.3\%), followed by 30 - 39 years which was $16(26.7 \%)$ and less than 20 years was $14(23.3 \%)$. Only 7 $(11.7 \%)$ cases were in the age group of 40 years and above. In group B majority were in the age group of $20-29$ years, which was 22 (36.7\%) followed by group $30-39$ years which was 17 (28.3\%) and less 20 years was 15 (25.0\%) cases.
Only $6(10.0 \%)$ cases were in the age group of 40 years and above.

Table II shows in both groups females were predominant which was $49(81.7 \%)$ and $49(81.7 \%)$ cases respectively and statistically significant.

Table III shows in group A moderate was in 21 $(35.0 \%)$ cases and severe in $39(65.0 \%)$ cases. In group B moderate was in $19(31.7 \%)$ and severe in $41(68.3 \%)$ cases.

Table-IV

Distribution of the patients by duration of episode before treatment $(n=120)$

\begin{tabular}{|c|c|c|c|}
\hline \multirow[t]{2}{*}{ Duration of episode } & \multicolumn{2}{|c|}{ Group } & \multirow[t]{2}{*}{ p value } \\
\hline & Group A(Sodium valproate) & Group B (Pizotifen) & \\
\hline Minutes & $1(1.7)$ & $0(.0)$ & 0.341 \\
\hline Minutes to hours & $40(66.7)$ & 35 (58.3) & \\
\hline Hours to days & 19 (31.7) & $25(41.7)$ & \\
\hline Total & 60 (100.0) & 60 (100.0) & \\
\hline
\end{tabular}

${ }^{*}$ Chi-square test was done to measure the level of significance.

Table-V

Distribution of the patients by frequency of migraine

\begin{tabular}{|c|c|c|c|c|}
\hline \multirow[b]{2}{*}{ Group } & \multicolumn{4}{|c|}{ Frequency of attack } \\
\hline & $\begin{array}{l}\text { Frequency of } \\
\text { attack per } \\
\text { month before } \\
\text { treatment }\end{array}$ & $\begin{array}{c}\text { Frequency of } \\
\text { attack per } \\
\text { month after } 2 \\
\text { months of } \\
\text { treatment }\end{array}$ & $\begin{array}{c}\text { Frequency of } \\
\text { attack per } \\
\text { month after } 4 \\
\text { months of } \\
\text { treatment }\end{array}$ & $\begin{array}{c}\text { Frequency of } \\
\text { attack per } \\
\text { month after } 6 \\
\text { months of } \\
\text { treatment }\end{array}$ \\
\hline Group A & $7.40 \pm 5.1$ & $4.69 \pm 3.46$ & $2.51 \pm 2.20$ & $1.60 \pm 1.87$ \\
\hline $\begin{array}{l}\text { (Sodium } \\
\text { valproate) }\end{array}$ & $(3-25)$ & $(2-20)$ & $(1-15)$ & $(1-10)$ \\
\hline $\begin{array}{l}\text { Group B } \\
\text { (Pizotifen) }\end{array}$ & $\begin{array}{c}9.25 \pm 7.21 \\
(2-30)\end{array}$ & $\begin{array}{c}6.56 \pm 5.14 \\
(1-20)\end{array}$ & $\begin{array}{c}3.88 \pm 2.83 \\
(1.12)\end{array}$ & $\begin{array}{c}2.76 \pm 1.98 \\
\quad(1-8)\end{array}$ \\
\hline$p$ value & 0.107 & 0.022 & 0.004 & 0.023 \\
\hline
\end{tabular}

Figure within parentheses indicates percentage. 
Table VI

Distribution of the patients by severity after treatment

\begin{tabular}{|c|c|c|c|}
\hline \multirow[t]{2}{*}{ Severity } & \multicolumn{2}{|c|}{ Group } & \multirow[t]{2}{*}{ p value } \\
\hline & $\begin{array}{c}\text { GroupA } \\
\text { (Sodium valproate) }\end{array}$ & $\begin{array}{c}\text { Group B } \\
\text { (Pizotifen) }\end{array}$ & \\
\hline Before treatment & & & 0.699 \\
\hline Moderate & $21(35.0)$ & $19(31.7)$ & \\
\hline Severe & $39(65.0)$ & $41(68.3)$ & \\
\hline Total & $60(100.0)$ & $60(100.0)$ & \\
\hline After 2 months of treatment & & & 0.667 \\
\hline Mild & $4(6.7)$ & $2(3.3)$ & \\
\hline Moderate & $43(71.7)$ & $43(71.7)$ & \\
\hline Severe & $13(21.7)$ & $15(25.0)$ & \\
\hline Total & $60(100.0)$ & 60 (100.0) & \\
\hline After 4 months of treatment & & & 0.234 \\
\hline Mild & $44(77.2)$ & $39(67.2)$ & \\
\hline Moderate & $13(22.8)$ & $19(32.8)$ & \\
\hline Total & $57(100.0)$ & $58(100.0)$ & \\
\hline After 6 months of treatment & & & 0.006 \\
\hline Mild & $24(96.0)$ & $24(66.7)$ & \\
\hline Moderate & $1(4.0)$ & $12(33.3)$ & \\
\hline Total & $25(100.0)$ & $36(100.0)$ & \\
\hline
\end{tabular}

${ }^{*}$ Chi-square test was done to measure the level of significance.

Figure within parentheses indicates percentage.

Table-VII

Distribution of the patients by duration of episode after treatment $(n=120)$

\begin{tabular}{|c|c|c|c|}
\hline \multirow[t]{2}{*}{ Severity } & \multicolumn{2}{|c|}{ Group } & \multirow[t]{2}{*}{ p value } \\
\hline & $\begin{array}{c}\text { GroupA } \\
\text { (Sodium valproate) }\end{array}$ & $\begin{array}{l}\text { Group B } \\
\text { (Pizotifen) }\end{array}$ & \\
\hline Before treatment & & & 0.341 \\
\hline Minutes & $1(1.7)$ & $0(0.0)$ & \\
\hline Minutes to hours & $40(66.7)$ & $35(58.3)$ & \\
\hline Hours to days & $19(31.7)$ & $25(41.7)$ & \\
\hline Total & $60(100.0)$ & $60(100.0)$ & \\
\hline After 2 months of treatment & & & 0.128 \\
\hline Minutes & $26(44.1)$ & $18(30.0)$ & \\
\hline Minutes to hours & 33 (55.9) & $40(66.7)$ & \\
\hline Hours to days & $0(0.0)$ & $2(3.3)$ & \\
\hline Total & $59(100.0)$ & $60(100.0)$ & \\
\hline After 4 months of treatment & & & 0.007 \\
\hline Minutes & $36(90.0)$ & $29(60.4)$ & \\
\hline Minutes to hours & $4(10.0)$ & $18(37.5)$ & \\
\hline Hours to days & $0(0.0)$ & $1(2.1)$ & \\
\hline Total & $40(100.0)$ & $48(100.0)$ & \\
\hline After 6 months of treatment & & & 0.010 \\
\hline Minutes & $22(88.0)$ & $20(51.3)$ & \\
\hline Minutes to hours & $3(12.0)$ & $18(46.2)$ & \\
\hline Hours to days & $0(0.0)$ & $1(2.6)$ & \\
\hline Total & $25(100.0)$ & $39(100.0)$ & \\
\hline
\end{tabular}

${ }^{*}$ Chi-square test wa-s done to measure the level of significance.

\#Figure within parentheses indicates percentage. 
Table IV shows in group A duration of episode in minutes was in $1(1.7 \%)$ case, minutes to hours in $40(66.7 \%)$ and hours to days in $19(31.7 \%)$. In group $B$ duration of episode in minutes to hours in $35(58.3 \%)$ and hours to days in $25(41.7 \%)$ cases.

Table $\mathrm{V}$ shows frequency of attack per month before treatment was $7.40 \pm 5.1$ and $9.25 \pm 7.21$ in group A and group B respectively $(p=0.107)$. Frequency of attack per month after 2 months treatment was $4.69 \pm 3.46$ and $6.56 \pm 5.14$ in group A and group B respectively $(p=0.022)$. Frequency of attack per month after 4 months of treatment was $2.51 \pm 2.20$ and $3.88 \pm 2.83$ in group $A$ and group $B$ respectively $(p=0.004)$. Frequency of attack per month after 6 months of treatment was1.60 \pm 1.87 and $2.76 \pm 1.98$ in group $A$ and group $B$ respectively $(p=0.023)$. and statistically significant.

Table VI shows in group A moderate and severe were $35.0 \%$ and $65.0 \%$ and in group $B$ moderate and severe were $31.7 \%$ and $68.3 \%$ respectively $(p=0.699)$. After 2 months of treatment severity was recorded in group $A$ mild, moderate and severe $6.7 \%, 71.7 \%$ and $21.7 \%$ cases and in group B mild, moderate and severe $3.3 \%, 71.7 \%$ and $25.0 \%$ of cases respectively $(p=0.667)$. After 4 months of treatment severity was recorded in group A mild and moderate $77.2 \%$ and $22.8 \%$ of cases respectively and in group $B$ mild and moderate $67.2 \%$ and $32.8 \%$ of cases respectively ( $p=$ 0.234 ). After 6 months of treatment severity was recorded in group A mild and moderate $96.0 \%$ and $4.0 \%$ and in group B mild and moderate $66.7 \%$ and $33.3 \%$ of cases respectively $(p=0.006)$ and was statistically significant.

Table VII shows, the duration of episode before treatment in group A minutes, minutes to hours and hours to days $1.7 \%, 66.7 \%$ and $31.7 \%$ and in group $B$ minutes, minutes to hours and hours to days $0.0 \%, 58.3 \%$ and $41.7 \%$ respectively $(p=0.341)$. After 2 months of treatment duration of episode was recorded in group A minutes, minutes to hours and hours to days $44.1 \%, 55.9 \%$ and $0.0 \%$ and in group $\mathrm{B}$ minutes, minutes to hours and hours to days $30.0 \%, 66.7 \%$ and $3.3 \%$ respectively $(p=0.128)$. After 4 months of treatment duration of episode was recorded in group $A$ minutes, minutes to hours and hours to days $90.0 \%$, $10.0 \%$ and $0.0 \%$ and in group $B$ minutes, minutes to hours and hours to days $60.4 \%, 37.5 \%$ and $2.1 \%$ respectively $(p=0.007)$. After 6 months of treatment duration of episode was recorded in group $A$ minutes, minutes to hours and hours to days $88.0 \%, 12.0 \%$ and $0.0 \%$ and in group $B$ minutes, minutes to hours and hours to days $51.3 \%$, $46.2 \%$ and $2.6 \%$ cases respectively $(p=0.010)$ and was statistically significant

\section{Discussion:}

In this present study a total of 120 patients were studied and divided into two groups, group-A and group B. The group-A took the sodium valproate and group-B took the pizotifen given with definite doses \& duration. In group-A majority were in the age group of 20-29 years which was 23 (38.3\%) followed by $30-39$ years which was $16(26.7 \%)$ and less than 20 years which was 14 (23.3\%). Only 7 $(11.7 \%)$ cases were in the age group of 40 years and above. In group-B majority were in the age group of 20 - 29 years which was $22(36.7 \%)$ followed by age group of 30 - 39 years which was $17(28.3 \%)$ and less 20 years which was 15 $(25.0 \%)$ cases. Only $6(10.0 \%)$ cases were in the age group of 40 years and above. It was reported in a study that migraine usually develops in childhood, adolescence or adulthood ${ }^{11}$. In a study ${ }^{12}$ it was also reported that headache intensity declined from 40 years to 74 years with change in headache frequency or duration which is consistent with this study and also consistent with the previous study done in Bangladeshi population ${ }^{13}$.

In both groups female was predominant which was 49(81.7\%) cases in group A and 49 (81.7\%) cases in group B. Pietrobon D and Striessnig J. reported that female was more vulnerable than male in respect to migraine which is consistent with this present study ${ }^{11}$. Russell et. al. ${ }^{14}$ found that there was a significant preponderance of females of all the subtypes of migraine which is also consistent with the present study and also consistent with the previous study done in Bangladeshi populations ${ }^{13}$. The pain severity before treatment revealed that, in group A moderate severity was in $35.0 \%$ cases and severe was in $65.0 \%$ cases \& in 
group B moderate was in $31.7 \%$ cases and severe was in $68.3 \%$ cases $(p=0.599)$. Duration of episode was recorded and it was revealed that in group $A$ minutes was in $1.7 \%$ case, minutes to hours was in $66.7 \%$ cases and hrs. to days was in $31.7 \%$ case. In group B minutes to hours was in $58.3 \%$ cases and hours to days was in $41.7 \%$ cases. Frequency of attack per month before treatment was $7.40 \pm 5.1$ and $9.25 \pm 7.21$ in group $A$ and group $B$ respectively ( $p=0.107)$. After 2 months of treatment severity was recorded in group A mild, moderate and severe $6.7 \%, 71.7 \%$ and $21.7 \%$ cases and in group B mild, moderate and severe $3.3 \%, 71.7 \%$ and $25.0 \%$ respectively $(p=0.667)$. After 4 months of treatment severity was recorded in group A mild and moderate $77.2 \%$ and $22.8 \%$ cases and in group B mild and moderate $67.2 \%$ and $32.8 \%$ respectively $(p=0.234)$. After 6 months of treatment severity was recorded in group $A$ mild and moderate $96.0 \%$ and $4.0 \%$ cases and in group B mild and moderate $66.7 \%$ and $33.3 \%$ respectively $(p=0.006)$. The difference was statistically significant $(p=0.009)$. After 2 months of treatment duration of episode was recorded in group A minutes, minutes to hours and hours to days $44.1 \%, 55.9 \%$ and $0.0 \%$ cases and in group $B$ minutes, minutes to hours and hours to days $30.0 \%, 66.7 \%$ and $3.3 \%$ cases respectively $(p=0.128)$. After 4 months of treatment duration of episode was recorded in group A minutes, minutes to hours and hours to days $90.0 \%, 10.0 \%$ and $0.0 \%$ cases and in group B minutes, minutes to hours and hours to days $60.4 \%, 37.5 \%$ and $2.1 \%$ cases respectively $(p=0.007)$. After 6 months of treatment duration of episode was recorded in group A minutes, minutes to hours and hours to days $88.0 \%, 12.0 \%$ and $0.0 \%$ cases and in group $B$ minutes, minutes to hours and hours to days $51.3 \%, 46.2 \%$ and $2.6 \%$ cases respectively $(p=0.010)$. The difference was statically significant $(p=0.01)$.

Frequency of attack per month after 2 months treatment was $4.69 \pm 3.46$ and $6.56 \pm 5.14$ in group A and group B respectively $(p=0.022)$. Frequency of attack per month after 4 months of treatment was $2.51 \pm 2.20$ and $3.88 \pm 2.83$ in group
$A$ and group $B$ respectively $(p=0.004)$. Frequency of attack per month after 6 months of treatment was $1.60 \pm 1.87$ and $2.76 \pm 1.98$ in group $A$ and group $B$ respectively $(p=0.023)$. The difference is statistically significant $(p=0.023)$ which is consistent with the previous study done in Bangladeshi populations ${ }^{13}$. So, sodium valproate is more beneficial than Pizotifen in the prophylaxis of migraine.

\section{Conclusion:}

The finding of this study permit to conclude that the efficacy of sodium valproate is more than Pizotifen in the prophylactic management of migraine patient.

\section{References:}

1. Headache Classification Subcommittee of the International Headache Society (HCSIHS) (2005). The International Classification of Headache Disorders, 2nd Edition, 1st revision. Retrieved 1st August, 2009 from: http://ihsclassification.org/en/0_downloads/

2. Charles A. Advances in the Basic and Clinical Science of Migraine. Ann Neurol, 2009; 65(5): 491-8.

3. International Headache Society. 2004, Headache Classification Committee of the International Headache Society. The international classification of headache disorders. 2nd ed. Cephalalgia 2004; 24(suppl 1): 1-160.

4. Rao BS, Das DG, Taraknath VR, Sarma Y, 'A double blind controlled study of propranolol and cyproheptadine in migraine prophylaxis', Neurol India, 2000; 48: 223.

5. Leonardi M, Steiner TJ, Scher AT, Lipton RB, 'The global burden of migraine: measuring disability in headache disorders with WHO's Classification of Functioning, Disability and Health (ICF)', J Headache Pain 2005; 6(6): 429-440.

6. Goadsby PJ, Lipton RB, Ferrari MD. Migraine-current understanding and treatment. N. Engl. J. Med 2002; 346: 257-70. 
7. Russell MB, Rasmussen BK, Thorvaldsen $P$, Olesen J. Prevalence and Sex-Ratio of the Subtypes of Migraine. Int. J. Epidemiol, 1995; 24 (3): 612-18.

8. Russell MB, Rasmussen BK, Thorvaldsen $P$, Olesen J. Prevalence and Sex-Ratio of the Subtypes of Migraine. Int. J. Epidemiol, 1995; 24 (3): 612-18.

9. Levy D, Strassman, AM, and Burstein R. "A critical view on the Role of Migraine Triggers in the Genesis of Migraine Pain" Headache,2009; 49(6): 953.

10. Boes CJ, Capobianco DJ, Cutter FM, Dodick, DW, Eross, EJ, Swanaon, JW. Headache and other craniofacial pains. In: Bradly WG, Daroff RB, Fenichel GM, Jankovic J, editors. Neurology in clinical practice. Vol. II, 4th ed. Philaldiphia: Butterworth-Heinemann, 2004; 2055-106.
11. Pietrobon D, Striessnig J. Neurobiology of Migraine. Neuroscience 2003; 4: 386-98.

12. Camarda R, Monastero R, Santangelo G, Migraine headaches in adolescents: A fiveyear follow-up study. Headache 2002; 42: 1000-5.

13. Hannan MA, Hasan MK, Begum A, Haque A, Ullah AKM, Khan RK et al. Study of epidemiological features of primary headache patients in a tertiary centre in Bangladesh. Bangladesh Journal of Neurosciences 2007; 23:13-20.

14. Russell MB, Rasmussen BK, Thorvaldsen $P$, Olesen J. Prevalence and Sex-Ratio of the Subtypes of Migraine. Int. J. Epidemiol, 1995; 24 (3): 612-18. 